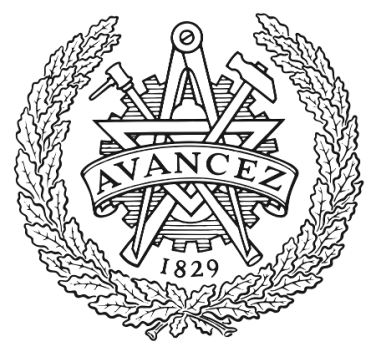

CHALMERS

UNIVERSITY OF TECHNOLOGY

\title{
Effects of in-company quality awards on organizational performance
}

Downloaded from: https://research.chalmers.se, 2023-04-26 11:11 UTC

Citation for the original published paper (version of record):

Eriksson, H., Johansson, F., Wiklund, H. (2003). Effects of in-company quality awards on organizational performance. Total Quality Management and Business Excellence, 14(2): 235-242. http://dx.doi.org/10.1080/1478336032000051421

N.B. When citing this work, cite the original published paper. 


\section{Total Quality Management \& Business Excellence}

\section{Effects of in-company quality awards on organizational performance}

\section{Henrik Eriksson , Fredrik Johansson \& H\%kan Wiklund}

To cite this article: Henrik Eriksson , Fredrik Johansson \& H\%kan Wiklund (2003) Effects of incompany quality awards on organizational performance, Total Quality Management \& Business Excellence, 14:2, 235-242, DOI: 10.1080/1478336032000051421

To link to this article: https://doi.org/10.1080/1478336032000051421

冓 Published online: 25 Aug 2010.

Submit your article to this journal $\sqsubset$

Џ Article views: 71

Q View related articles $\sqsubset$

C7 Citing articles: 8 View citing articles 


\title{
Effects of in-company quality awards on organizational performance
}

\author{
HENRIK ERIKSSON ${ }^{1}$, FREDRIK JohaNSSON ${ }^{1} \&$ HÅkAN WIKLUND ${ }^{1,2}$ \\ ${ }^{1}$ Division of Quality Technology and Statistics, Luleå University of Technology, SE-97187 Luleå, \\ Sweden $\mathcal{G}^{2}$ Mid Sweden University, SE-831 25 Östersund, Sweden
}

ABSTRACT The relationship between total quality management (TQM) practices and improved performance has been frequently discussed in the literature. In this paper, the costs and the effects of in-company quality awards on performance are discussed and analysed. The paper covers a survey of Swedish companies that use or have used in-company quality awards to stimulate TQM efforts and thereby to improve performance. The study cannot show any strong evidence of improved performance for units that applied for the in-company quality award. However, in contrast to units that have not applied, some units that have applied for the in-company quality award considered that the results related to performance have improved greatly. One large positive effect perceived by the participating units was increased customer orientation while the largest costs were put on the description of activities and the improvement work itself.

\section{Introduction}

The relationship between total quality management (TQM) practices and performance is frequently discussed. For example, some researchers state that TQM programmes are ineffective (Harari, 1997). Bergquist \& Ramsing (1999) and Przasnyski \& Tai (1999) argue that it is difficult to establish a relationship between TQM and the profitability of the organization. On the other hand, results have also been published that state that a successful implementation of TQM resulted in increased performance of the organisation, e.g. Lemak \& Reed (1997) and Hendricks \& Singhal (1999). Some of the research into the relationship between performance and systematic TQM efforts is conducted by comparing companies that have made quality investments-often quality award recipients-with other 'control companies', which have not made such an investment, e.g. Hendricks \& Singhal (1997) and Bergquist \& Ramsing (1999).

One way to stimulate a company culture based on the core values of TQM is to work with a quality award. Today, the spectrum of different quality awards is quite large and covers international, national, regional, branch-wise and in-company quality awards. Some examples of quality awards that have been used by many organizations and are relatively widespread are the Malcolm Baldrige National Quality Award (MBNQA) and the European Quality Award (EQA). In many countries, however, the development of national quality awards is still new or non-existent (Chuan \& Soon, 2000). For a thorough list of quality

Correspondence: Henrik Eriksson, Division of Quality Technology and Statistics, Luleå University of Technology, SE-97187 Luleå, Sweden 
awards and a comparison between different awards, see for example Hagen (2000) or Vokurka et al. (2000).

Svensson \& Klefsjö (2000) have suggested different phases of the award process. They argue that the self-assessment that is used in the award process has four phases, similar to the Deming cycle. The first phase, 'planning', includes asking questions such as: why should we perform a self-assessment? When should the work be done? Who should be involved? Which model should be used as a basis for the description? The second phase, 'do', consists of obtaining a description of the organization's way of working. The third phase, 'study', consists of the analysis of the description and the forth phase, 'act', consists of planning for improvements. These phases are similar in the different kinds of awards, e.g. international, national, regional, branch-wise and in-company quality awards.

The main difference between these awards is the group of units and companies at which the award is aimed. For example, only units within an organization can apply for an incompany quality award, while the national quality award is open to all organizations/units in the country. One possible benefit of an in-company quality award in comparison with a national quality award is that it is easier for units to benchmark and learn the best practices since access to the recipient of an in-company quality award is easier. Further, van der Wiele et al. (1996) claim that both internal and external learning in terms of best practices and transfer of ideas is taking place when performing self-assessment, and this procedure contributes to the improvement of the performance of organizations.

Myers \& Heller (1995) claim that $80 \%$ of the organizations within AT\&T have used its in-company quality award, called the Chairman's Quality Award (CQA), to assess each other. Based on the processes and criteria of the Malcolm Baldrige National Quality Award, the CQA process consists of site visits and award criteria such as leadership, strategic quality planning and customer focus. The in-company quality award of AT\&T shows a great increase in average scores from the units that applied over the years (Myers \& Heller, 1995). However, it is not clear whether the increase in average scores for the in-company quality award of AT\&T comes from improved bottom line results or if the units improve the process, including writing skills, when applying for the award a second and third time. In another paper, Hannukainen \& Salminen (1998) discuss Nokia's current state analysis programme, which has many similarities to the in-company quality awards in this paper. This programme is tailored to fit Nokia and consists of five different areas; leadership, customer, planning, process and people. By this successful programme, Nokia asks its people around the globe to establish the most challenging performance targets based on their self-assessment of process capability.

Today, there are some companies in Sweden that are working with in-company quality awards. There are also companies that have ended or are ending their work with in-company quality awards. Our literature studies indicate that no independent evaluation has been made to estimate the costs and effects of in-company quality awards, and to investigate whether incompany quality awards in fact increase the performance of the company. In this paper, the impact of in-company quality awards on performance is analysed by studying units that have applied for an in-company quality award and by comparing these units with units that have not applied for an in-company quality award. In addition, other relevant effects of the incompany quality award are studied and the costs associated with the work of in-company quality awards are estimated.

\section{Method}

In Sweden, there are five companies that have, or have had, an in-company quality award. One of these companies, the Swedish Telecom operator (Telia), ended its in-company quality 
award in 1995. This company was not included in the study due to the difficulties for the people within the company remembering and estimating the effects and costs of the incompany quality award. Furthermore, Vattenfall, which had had an in-company quality award, was not included in the study owing to large reorganizations. In this case, the reorganization made it impossible to reconstruct the original units that once applied for the in-company quality award.

A questionnaire was prepared in order to collect the data. The questionnaire will also serve as an input to further qualitative studies, on the effects of in-company quality awards, which will validate the results from this study. In total, this study covers three different companies-the Swedish National Road Administration ('Vägverket'), Sydkraft (a supplier of electricity) and the Swedish Post ('Posten'). The questionnaire was sent to 77 units within these three companies. The respondents of the questionnaire were heads of these units. The response rate to the questionnaire was $66 \%$.

When evaluating the performance it is crucial first to identify appropriate key-indicators. Input regarding appropriate key-indicators came mainly from the General Accounting Office study (GAO, 1991), which is often referred to in the literature discussing benefits of TQM. In the GAO study, 20 companies that were among the highest-scored applicants in 1988 and 1989 for the Malcolm Baldrige National Quality Award were evaluated in four different groups of key-indicators:

- customer satisfaction indicators (called key-indicators of customers in this study)

- operating indicators (called key-indicators of processes in this study)

- employee indicators (called key-indicators of employees in this study)

- financial performance indicators (called key-indicators of owners in this study).

Similar areas of key-indicators are also used in the Balanced Scorecard (Kaplan \& Norton, 1996). Bergquist \& Ramsing (1999) and Zairi et al. (1994) also use these key-indicators in order to determine the effects of TQM practice on the performance. See also Shetty (1993), who makes a thorough discussion concerning the results of the GAO study. The main result from the GAO study, and from articles discussing the results from the GAO study, is that TQM practices do improve bottom line results. The GAO study further showed that better employee relations, improved operating procedures, greater customer satisfaction and an increased financial performance were achieved through TQM practices.

In order to find out if the key-indicators from the GAO study were appropriate in this study, the quality managers of the surveyed companies were used as a reference group. As a result, some of the key-indicators from the GAO study were not included in the questionnaire, while others were added to describe better the companies' activities and results. However, the groups of key-indicators remained the same.

In 1998, two of the surveyed companies initiated their in-company quality award and one company started in 1997. To be able to study the same time period for all the surveyed companies, 1998 was chosen as an approximate starting time for the development of the keyindicators. Hence, the respondents of the questionnaire were asked to estimate the development of the key-indicators from 1998 until the end of 2001. It took an average of two and a half years for the companies in the GAO study to notice the benefits with TQM. Therefore, a period of four years was considered to be enough time to study the results from the use of the in-company quality award.

The surveyed units that applied for the in-company quality award were also asked to estimate the work effort performed in each of the four phases identified by Svensson \& Klefsjö (2000). In addition to these phases, training was included in the questionnaire. In order to apply for an in-company quality award the unit has to train its employees in TQM 
and self-assessment. Training was therefore identified as a fifth phase. Hence, the phases or costs that were included in the questionnaire were planning, training, description of activities, analysis of descriptions and improvements.

\section{Results}

The questionnaire was divided into four parts. First, all the respondents were asked to estimate the development of the key-indicators within the four groups of customers, processes, employees and owners, from the beginning of 1998 until the end of 2001. Second, the respondents that have worked with an in-company quality award were asked to state some effects of the in-company quality award and estimate the importance of the effect on customers, processes, employees and owners. Third, the respondents that worked with the in-company quality award were asked to estimate the costs of applying for an in-company quality award with the phases suggested by Svensson \& Klefsjö (2000). Fourth, all the respondents were asked to give some general opinions about in-company quality awards. The respondents of the questionnaire were divided into three groups:

(a) units that have not applied for the in-company quality award,

(b) units that applied once for the in-company quality award,

(c) units that applied twice or more times for the in-company quality award.

For a thorough presentation of the results from the questionnaire, including the development of all the key-indicators, see Eriksson (2002). However, the general development of the keyindicators and other relevant indicators that the unit used to measure the results within the four groups (customers, processes, employees and owners) are displayed in Figs 1-4.

As shown in Figs 1-4, only units that applied one or more times perceived great improvements for the four groups of key-indicators.

Part two of the questionnaire was used to analyse other relevant effects of the work with in-company quality awards. One large positive effect stated by the respondents that worked with the in-company quality award was increased customer orientation. Increasing customer satisfaction is also one of the main aims with TQM. Other effects that the respondents mentioned were increased focus on improvements, processes, quality, results and an increased

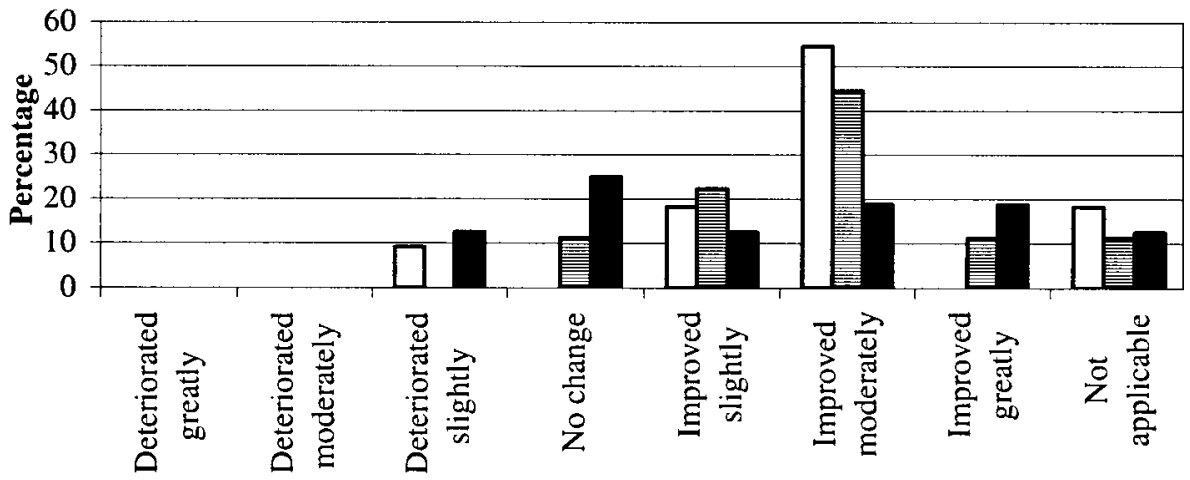

$\square$ Applied no time

目 Applied once

Applied two or more times

Figure 1. The figure shows the percentage of the answers for each alternative regarding the general development of key-indicators of customers. The units were divided into three groups: units that have not applied, units that applied once and units that applied twice or more times for the in-company quality award. 


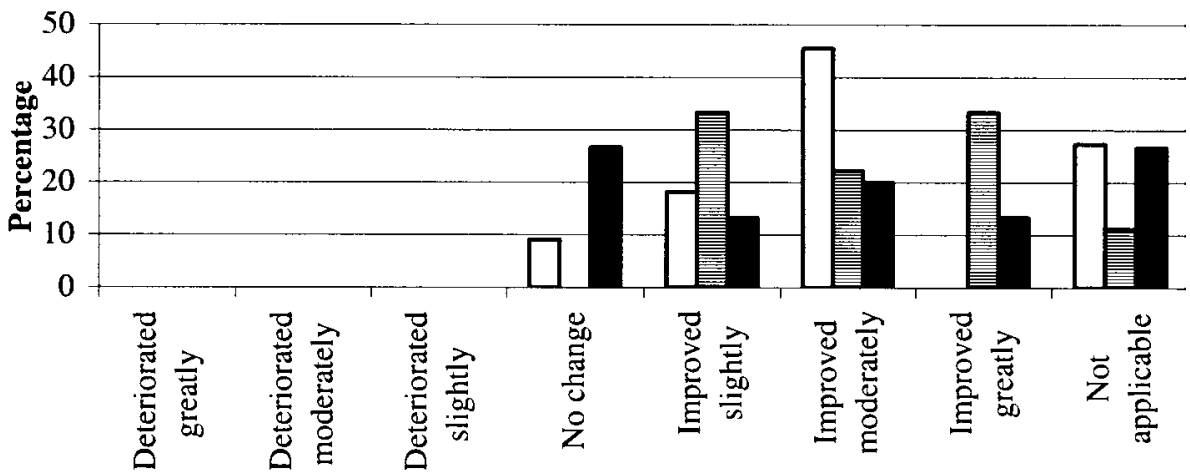

$\square$ Applied no time

曾 Applied once

Applied two or more times

Figure 2. The figure shows the percentage of the answers for each alternative regarding the general development of key-indicators of processes. The units were divided into three groups: units that have not applied, units that applied once and units that applied twice or more times for the in-company quality award.

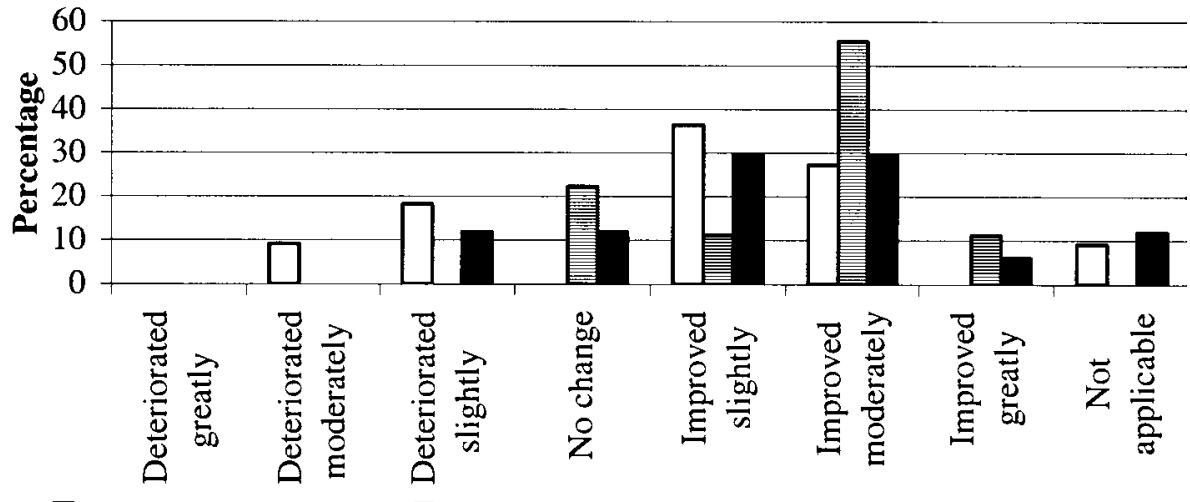

$\square$ Applied no time

国 Applied once

Applied two or more times

Figure 3. The figure shows the percentage of the answers for each alternative regarding the general development of key-indicators of employees. The units were divided into three groups: units that have not applied, units that applied once and units that applied twice or more times for the in-company quality award.

comprehensive view of the business. Some of the perceived effects have many similarities to the core values in the self-assessment model used in the in-company quality awards, such as customer orientation, a focus on improvements and processes.

In the questionnaire, the respondents that have worked with the in-company quality award were also asked to estimate the importance of the effects mentioned above for employees, processes, owners and customers. The respondents considered that the effects of the in-company quality award had the largest importance to employees, while owners were ranked second, processes third and the smallest effect was on the customers. The strong impact that the effects had on the employees should be able to increase the TQM-culture within those units that applied for the in-company quality award, which can result in longterm advantages for those units.

Part three of the questionnaire included an estimation of the costs for the units with the in-company quality award. The median costs for the units applying for the in-company 


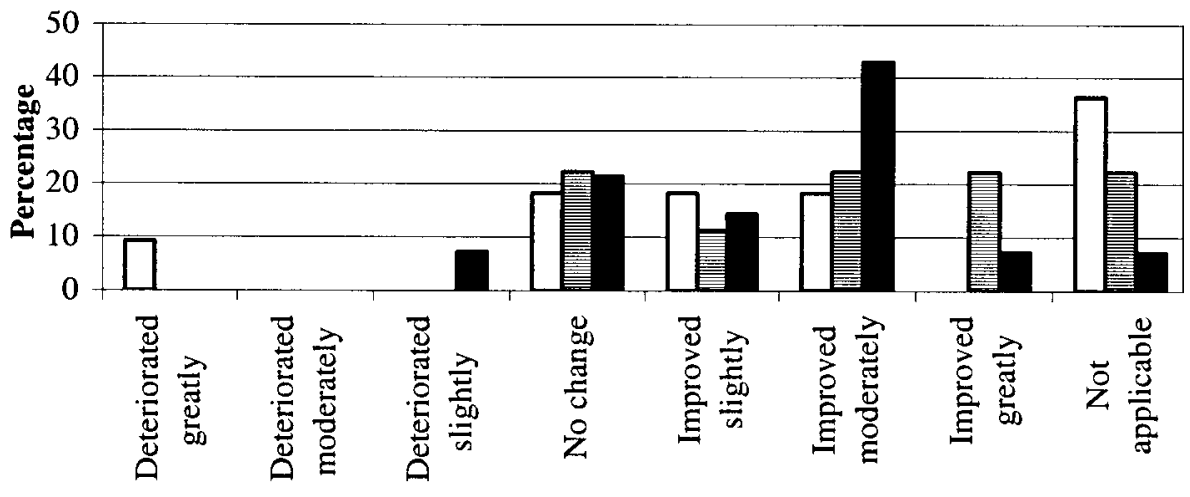

$\square$ Applied no time

国 Applied once

Applied two or more times

Figure 4. The figure shows the percentage of the answers for each alternative regarding the general development of key-indicators of owners. The units were divided into three groups: units that have not applied, units that applied once and units that applied twice or more times for the in-company quality award.

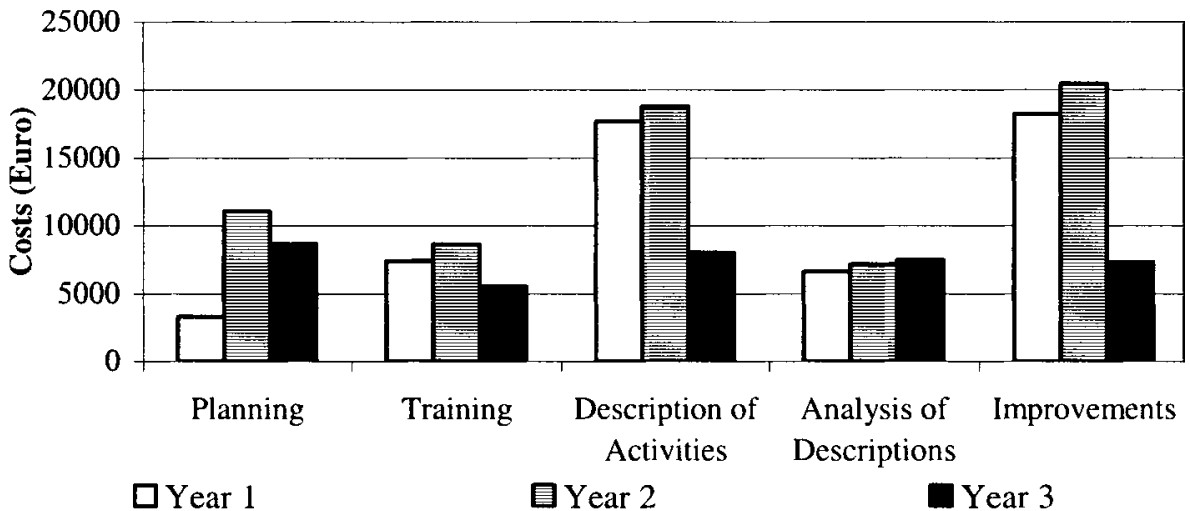

Figure 5. The figure shows the median costs in euros for the units that applied for the in-company quality award. The costs are divided into the different phases and into different years for the application.

quality award are displayed in Fig. 5. The costs were divided into the different phases of the in-company quality award and into different years for the application.

The largest costs with the in-company quality award, according to Fig. 5, were considered to be the description of activities and the improvement work that followed. However, the spread was largest for the phase of improvements, but also quite large for all the phases. The median cost for a unit to apply for an in-company quality award in the first year was considered to be $€ 58000$. The median cost increased to $€ 64000$ the second year, while it decreased to $€ 46000$ the third year the unit applied for the in-company quality award.

In part four, questions regarding the respondents' general opinions of the in-company quality award were asked. Overall, $77 \%$ of the respondents that applied for the in-company quality award stated that they have a positive attitude towards the in-company quality award, while $62 \%$ of the respondents that have not applied stated that they have a positive attitude towards the in-company quality award. Only $4 \%$ of the respondents that applied for the incompany quality award had a negative attitude, and $15 \%$ of the respondents that did not 
apply stated the same attitude. The rest of the respondents had neither a positive nor a negative attitude.

Furthermore, $68 \%$ of the respondents that applied for the in-company quality award considered that the in-company quality award is profitable, while $42 \%$ of the respondents that have not applied considered, even if they did not apply, that the in-company quality award is profitable. In addition, $20 \%$ of the respondents that applied for the in-company quality award did not perceive any profitability, and $25 \%$ of the respondents that have not applied shared that opinion. The rest of the respondents did not have an opinion regarding the profitability of the in-company quality award.

\section{Discussion}

In order to increase the reliability of this study and to make it possible for other people to repeat the study, the questionnaire and a more detailed description of the study is presented in Eriksson (2002). To increase the validity of the study, two main activities were performed. First, the questionnaire was reviewed both internally and externally in order to correct for misinterpretations and other flaws. Second, a non-response analysis was performed. The main purpose of the non-response analysis was to investigate whether the opinion of respondents that did not answer differed from the ones that answered the questionnaire. Fifteen units that did not answer the questionnaire were randomly selected and asked if they could fill in the questionnaire. A higher percentage of the respondents in the non-response analysis stated that their unit had not applied for the in-company quality award. However, there was no clear evidence that the managers that did not answer the questionnaire in the first place differed in their opinion, regarding the key-indicators and their attitude to the incompany quality award, compared with the group that did answer.

\section{Conclusions}

Even if this study includes units that were not necessarily among the highest-scored applicants, such as those included in the GAO study, some positive effects on the performance have been identified. Some units that applied for the in-company quality award experienced that the general development of the key-indicators were improved greatly for all the four groups of keyindicators, while none of the units that have not applied stated the same positive development. However, one may argue that the development of the key-indicators does not differ much between the groups of units. Some perceived positive effects of the in-company quality award have been identified, such as an increased customer orientation. The remarkable thing is that the identified effects had the largest importance to the employees and not to the customers, owners or processes of the company. The largest costs perceived by the respondents were the description of activities and the improvement work itself. Further qualitative studies will be performed in order to validate the results from this study and to understand better the effects of in-company quality awards.

\section{Acknowledgements}

The authors would like to acknowledge the financial support of the Swedish National Road Administration ('Vägverket') and the Swedish Institute for Quality (SIQ). The authors would also like to thank Professor Bengt Klefsjö for valuable comments. 


\section{H. ERIKSSON ET AL.}

\section{References}

Bergquist, T. \& RAmsing, K. (1999) Measuring performance after meeting award criteria, Quality Progress, 32(9), pp. 66-72.

Chuan, T.K. \& Soon, L.C. (2000) A detailed trends analysis of national quality awards world-wide, Total Quality Management, 11(8), pp. 1065-1088.

ERIKsson, H. (2002) The effects of in-company quality awards. Research Report 2002:1, Division of Quality Technology and Statistics, LuleÅ University of Technology, Luleå.

GAO (1991) Management Practices: US companies improve performance through quality efforts. Report no. GAO/NSIAD-91-190. Washington DC, US General Accounting Office (GAO).

HAGEN, M.R. (2000) Quality Awards listing, Quality Progress, 33(8), pp. 64-74.

HANNuKaINEN, T. \& Salminen, S. (1998) Setting the course for quality: a case study in applied self-assessment, Proceedings from the 52nd Annual Quality Congress, ASQ, Philadelphia, pp. 316-323.

HARARI, O. (1997) Ten reasons why TQM doesn't work, Management Review, 86(1), pp. 38-44.

HENDRICKS, K.B. \& SINGHAL, V.R. (1997) Does implementing an effective TQM program actually improve operating performance? Empirical evidence from firms that have won quality awards, Management Science, 43(9), pp. 1258-1274.

HendRICKs, K.B. \& Singhal, V.R. (1999) Don't count TQM out, Quality Progress 32(4), pp. 35-40.

Kaplan, R. \& Norton, D. (1996) The Balanced Scorecard. Translating strategy into action (Boston, Harvard Business School Press).

Lemak, D. \& ReED, R. (1997) Commitment to total quality management: is there a relationship with firm performance, fournal of Quality Management, 2(1), pp. 67-86.

Myers, D.H. \& Heller, J. (1995) The dual role of AT\&T's self-assessment process Quality Progress, 28(1), pp. $79-83$.

PRZASNYSKI, Z. \& TAI, L. (1999) Stock market reaction to Malcolm Baldrige National Quality Award announcements: Does quality pay?, Total Quality Management, 10(3), pp. 391-200.

SHETTY, Y.K. (1993) The quest for quality excellence, Advanced Management fournal, 58(1), pp. 34-40.

Svensson, M. \& KLEFSJö, B. (2000) Experience from creating a quality culture for continuous improvements in the Swedish school sector by using self-assessments, Total Quality Management, 11(4/5\&6), pp. 800-807.

Van der Wiele, A., Williams, A.R.T., Dale, B.G. Carter, G., Kolb, F., Luzon, D.M., Schmidt, A. \& WALlaCe, M. (1996) Self-assessment. A study of progress in Europe's leading organizations in quality management practices, International fournal of Quality and Reliability Management, 13(1), pp. 84-104.

Vokurka, R.J., Stading, G.L. \& Brazeal, J. (2000) A comparative analysis of national and regional Quality Awards, Quality Progress 33(8), pp. 41-49.

Zairi, M., LeTZA, S.R. \& OAKLAND, J.S. (1994) Does TQM impact on bottom-line results?, The TQM Magazine, 6(1), pp. 38-43. 